\title{
El republicanismo de los radicales como valor y como amenaza para la república Una perspectiva antropológica
}

Fernando Alberto Balbi ${ }^{1,2}$ *

1 Universidad de Buenos Aires. Facultad de Filosofía y Letras. Instituto de Ciencias Antropológicas. Sección Antropología Social. Buenos Aires, Argentina.

2 CONICET. Buenos Aires, Argentina

Correo electrónico: fabalbi@yahoo.com.ar

\section{Resumen}

En este artículo examino la aparente contradicción entre las declaraciones recurrentes de los dirigentes y militantes de la Unión Cívica Radical sobre la orientación republicana de sus prácticas políticas y las características efectivas de estas, que frecuentemente ignoran normas y formas de las instituciones de la república y hasta llegan a atentar en contra de ellas. Desde una perspectiva antropológica, sugeriré que tanto esas preocupaciones moralizantes como esas prácticas deben ser consideradas en relación con ciertas orientaciones cognitivas y morales desarrolladas a lo largo de la historia del radicalismo y que, desde ese punto de vista, se implican mutuamente.

\section{The republicanism of the Radical Civic Union as a value and a threat to the Republic: an anthropological perspective}

\begin{abstract}
This article examines the apparent contradiction between the recurrent statements of leaders and activists of the Radical Civic Union regarding the republican orientation of their political practices and the effective characteristics of these, which often ignore the institutional rules and forms of the republican institutions and even attack them. Adopting an anthropological stance, I will suggest that both moralizing concerns and political practices should be considered in relation to certain cognitive and moral orientations developed throughout the history of the party and that, from that point of view, they implicate each other.
\end{abstract}

Recibido

diciembre de 2017

Aceptado

Mayo de 2018

Palabras clave

Antropología Social; Antropología de la Política; Moral; Cognición; Unión Cívica Radical

\section{Key words}

Social Anthropology; Anthropology of Politics; Morals; Cognition; Radical Civic Union 


\section{O republicanismo dos radicais como valor e como ameaça para a república: uma perspectiva antropológica}

\section{Resumo}

Palavras-chave

Antropologia Social; Antropologia da Política; Moral; Cognição; União Cívica Radicall
Neste artigo, examino a aparente contradição entre as declarações recorrentes dos líderes e militantes da União Cívica Radical quanto à orientação republicana de suas práticas políticas e as características efetivas dessas que, frequentemente, ignoram as normas e as formas das instituições da república e até acabam atentando contra elas. Adotando uma perspectiva antropológica, sugiro que essas preocupações moralizantes assim como as práticas devem ser consideradas em relação a determinadas orientações cognitivas e morais desenvolvidas ao longo da história do radicalismo e que, desde esse ponto de vista, se relacionam entre si.

\section{Introducción}

En su libro El cambio y la impostura, Ezequiel Adamovsky (2017) muestra cómo "el par binario 'el populismo' vs. 'la República' organizó en los últimos años todo el debate público" (p. 75) y detalla las formas en que políticos, medios de comunicación, periodistas e intelectuales contribuyeron a imponerlo. En un pasaje central de su argumentación, el autor afirma que:

el republicanismo es hoy dos cosas diferentes y contrapuestas. Por un lado, se trata
de una tradición de ideas y valores reivindicable para toda sociedad que aspire a
una democracia vigorosa y a una vida justa. Pero por el otro, funciona como un
discurso ideológico que habita no solo en el terreno de la filosofía, sino también en los
conceptos, ideas e imágenes que utilizamos de manera cotidiana para comprender
el mundo. Da forma a nuestro sentido común y orienta nuestras conductas ynuestra
percepción de la realidad. [...] En fin, la palabra 'república' ha sido capturada por
agendas y prácticas políticas que poco tienen que ver con sus orígenes más gloriosos.
La retórica de 'lo republicano', tanto en Argentina como en el resto del mundo, está
hoy en manos de las derechas y de viejos progresistas que inadvertidamente se
ven imantados hacia ellas, 'La República', artículo retórico, conspira hoy contra la
República entendida como valor substantivo. [...] Las frecuentes dobles varas en la
evaluación de las agresiones a la República según quiénes sean sus protagonistas son
la manifestación más clara de ese carácter ideológico. (Adamovsky, 2017, pp. 62 y 63)

Quiero detenerme sobre esa relación problemática entre los valores republicanos y los usos políticos de las apelaciones a la república a que se refiere Adamovsky. Pero quiero hacerlo apartándome de la disyunción absoluta que él traza entre unos y otros para sugerir que sus relaciones son más complejas y examinar cómo se presentan en el caso particular de los radicales. No pretendo refutar a Adamovsky, sino apenas introducir algunos matices que asocio con la mirada propia de la antropología social (Balbi, 2012): la atención a la variabilidad de los hechos sociales y a las perspectivas nativas. En efecto, parece dudoso asumir que los radicales llegaran a representar su enfrentamiento con el kirchnerismo como una defensa de la república de la misma manera en que lo han hecho los miembros del PRO o algunos peronistas; así como es difícil dar por sentado que sus respectivas maneras de entender sus propias actividades políticas sean idénticas, pues cada uno de estos sectores tiene su propia trayectoria y antecedentes 
distintivos en lo tocante a sus formas de hacer política. De lo que se trata, entonces, es de complejizar la cuestión atendiendo a la variedad de formas particulares de entender y de hacer política que se encuentran en la base del profuso despliegue de este recurso político que caracteriza a los últimos años: se trata, esto es, de explorar cómo llega a ser un recurso para ciertos actores políticos. Y me detendré particularmente en el caso del radicalismo porque es allí donde las 'contradicciones' y 'dobles varas'1 de que habla Adamovsky resultan más llamativas, habida cuenta de su larguísima trayectoria de representación de su propia existencia en términos que se basan en el postulado -que ha revestido diversas formas a lo largo del tiempo- de que existiría una relación privilegiada entre la Unión Cívica Radical y la institucionalidad de la nación argentina.

A lo largo de la historia de la UCR se encuentra recurrentemente una tendencia de sus órganos, dirigentes y militantes a representarse sus acciones y la existencia misma de su partido como inextricablemente ligados a la tarea de defender, preservar, sanear, etc. las instituciones de la República, ${ }^{2}$ representaciones que se condensan en la idea de que los radicales y la UCR se caracterizarían por su republicanismo o su vocación cívica. Se trata de representaciones lo bastante bien fundadas como para ser compartidas por muchos observadores e incluso por numerosos adversarios políticos de los radicales. Por otro lado, con similar constancia se verifica que el accionar efectivo de los radicales y sus órganos partidarios ignora normas y formas de las instituciones republicanas (como, por ejemplo, en el irregular procedimiento por el cual en enero de 2016 fue ampliada la Corte Suprema de la provincia de Jujuy por iniciativa del gobernador radical Gerardo Morales) o incluso que atenta directamente contra ellas (como ocurriera con todos los golpes de Estado del siglo XX, que fueron activamente alentados por figuras del radicalismo y dieron lugar a gobiernos de facto a los que este aportó más funcionarios que ninguna otra formación partidaria). Esto, desde luego, no significa que las prácticas políticas de los radicales no se encuentren muchas veces efectivamente orientadas hacia objetivos relacionados con la depuración o el rediseño de las instituciones republicanas en vistas de su mejoramiento. Sin embargo, veremos que sus relaciones de larga data con cierta forma de entender los valores republicanos y la misión de su propio partido los hacen propensos a desarrollar prácticas políticas que ponen en riesgo a las instituciones de la república.

Nos encontramos, pues, ante ese tipo de contradicción aparente entre lo que los actores dicen y lo que hacen, que -como enseña la historia de la antropología social- es un aspecto de la complejidad de la vida social que demanda ser examinado. Por lo demás, esa misma historia muestra claramente la enorme productividad analítica del examen de todo lo que, desde el punto de vista del observador, aparece como contradictorio, paradójico o ambiguo (Balbi, 2007).

Se trata, en lo fundamental, de abordar las relaciones efectivas de los radicales con las instituciones de la república en función del análisis de sus perspectivas nativas (Balbi, 2012) al respecto. En particular, pondré el foco sobre lo que llamo su 'republicanismo'; esto es, la mutua implicación entre, por un lado, la forma en que los radicales suelen representarse su accionar y la existencia misma de su partido como inextricablemente ligados a la tarea de defender, preservar y perfeccionar las instituciones de la República; y por el otro, la frecuencia con que esas acciones apuntan a establecer un control sobre dichas instituciones y a usarlas con fines políticos incluso si ello implica pasar por alto sus formalidades y hasta atentar directamente contra ellas. El punto clave es que no se trata meramente de una supuesta suma de dos tendencias independientes una de la otra, sino de su inextricable combinación como componentes de una cierta orientación general de las prácticas políticas de los radicales.

Ahora bien, un abordaje completo de este tema excede largamente a estas páginas, así como a mis posibilidades actuales. Por un lado, mostrar que el republicanismo
1. Empleo las comillas simples para enfatizar y/o relativizar algunos términos y expresiones.

2. Me valgo de las itálicas para denotar los términos y expresiones empleados habitualmente por los actores. 
3. El análisis que sigue se basa en una revisión de la producción historiográfica y de ciencias sociales sobre la historia del radicalismo y, secundariamente, en un seguimiento de la política nacional contemporánea que he desarrollado mediante la prensa y de la literatura académica al respecto. No he realizado un trabajo de campo etnográfico en torno de las prácticas políticas de los dirigentes y militantes radicales y exradicales, sino que me he limitado a abordar las fuentes mencionadas desde una perspectiva antropológica. informa habitualmente las prácticas políticas de los radicales en el contexto actual exigiría presentar un análisis etnográfico y comparativo de diversos procesos políticos contemporáneos que en este momento no puedo ofrecer. Por el otro, para evitar la reificación de cualquier elemento atribuido a las perspectivas nativas es preciso dar cuenta de los fenómenos etnográficamente, examinando, por un lado, los procesos sociales que les dieron origen y, por el otro, aquellos que los reproducen (Balbi, 2007). Ello supondría, en este caso, historiar la forma aparentemente contradictoria en que los radicales entienden y desarrollan sus relaciones con las instituciones de la república, es decir, mostrar cómo llegó a conformarse, qué factores han propiciado su reproducción en el pasado y cuáles lo hacen en la actualidad; asimismo, requeriría abordar etnográficamente su relativa heterogeneidad y sus variaciones. Empero, considerando que la existencia de la UCR se remonta a casi ciento treinta años, dichas tareas son claramente irrealizables en este breve texto. Me limitaré, entonces, a delinear la forma característica en que los radicales se representan el tema de la defensa de las instituciones republicanas y de la relación de la UCR con ese objetivo, y a mostrar cómo se gestaron sus líneas centrales, y dejaré los problemas de su reproducción posterior y sus variaciones, así como el análisis de casos contemporáneos, para otras oportunidades. ${ }^{3}$

\section{Concepciones nativas de política: pragmatismos y axiologías}

El tema de las aparentemente contradictorias relaciones de los radicales con las instituciones republicanas invita a considerarlas como meramente interesadas o puramente pragmáticas. Sería muy sencillo concluir que el republicanismo de los radicales no es más que una retórica eficaz mediante la cual ellos justifican acciones y cursos de acción políticos cuyo principio de producción es una disposición pragmática a concretar determinados intereses. Sin embargo, como he mostrado anteriormente (Balbi, 2007, 2014, 2017), el pragmatismo en estado puro no puede ser sino una auténtica rareza sociológica, porque la moral forma parte de los recursos cognitivos mediante los cuales los actores conciben sus intereses y avanzan en su realización. Así, las orientaciones pragmáticas de los seres humanos están siempre fundadas en escalas de preferencia socialmente específicas que se encuentran inscriptas en sus recursos cognitivos y que combinan inextricablemente valoraciones prácticas y morales.

Hablar del conocimiento implica hacer referencia a estructuras conceptuales y de percepción socialmente informadas que se encuentran en la base de la acción humana y operan más o menos directamente como principios de su producción (Balbi, 2016a). Así, considerar a la moral como un aspecto de la cognición implica entenderla como un rasgo de las diversas formas de conocimiento que sujetos socialmente situados producen, despliegan y se imponen unos a otros en el curso de su producción cooperativa del mundo social (Balbi, 2016b). Lo distintivo de la moral es la postulación eficaz en determinado medio social de ciertos cursos de acción, formas de relación social, arreglos institucionales, etc., como simultánea e indisociablemente deseables y obligatorios (Balbi, 2016a, 2017). Desde este punto de vista, entonces, la moral puede ser entendida como un tejido, siempre en hechura, de conocimientos y prácticas referidos a la deseabilidad y obligatoriedad relativas de los cursos de acción y las relaciones sociales que, al tiempo que responden a ellos, los configuran y reconfiguran sobre la marcha (Balbi, 2016a, 2016b).

Ahora bien, si la moral es parte de la cognición, lo es tanto de sus formas más reflexivas (los conocimientos verbalizados, que suponen en mayor o menor medida las mediaciones que introduce la elaboración discursiva de nuestras percepciones y conceptualizaciones) como de las más intuitivas (los conocimientos tácitos e incorporados, que se encuentran directamente implicados en nuestra percepción, de modo tal que los hechos se nos presentan de manera naturalizada, como si estuviesen dotados en sí mismos 
de un sentido determinado). A medida que se pasa de unas a otras, se encuentran algunos conocimientos muy difícilmente accesibles a la conciencia de los actores, que son "cada vez menos susceptibles de ser separados de los procesos que los producen" pero también son, "de muchas formas, los más importantes porque son aquello que permite a la gente operar en el mundo" (Bloch, 2012, p. 144, mi traducción). Se trata del plano del "entendimiento", que "no consiste meramente en reflexiones desarrolladas después de los hechos sobre la experiencia previa" -aunque, sin duda, estas contribuyen a su reproducción- sino que, en lo fundamental, es "la manera en que (o los medios a través de los cuales) tenemos esa experiencia", esto es, "el modo en que el mundo se nos presenta" (Johnson, 1992, p. 104, mi traducción).

Puesto que la moral no solo opera en el plano de las formas de conocimiento elaboradas discursivamente, sino que lo hace primariamente como parte del entendimiento, ella contribuye a dar forma al sentido de las acciones propias y ajenas, de la materialidad del mundo social, etc. (Balbi, 2016a, 2017). Dicho de otra manera, la moral es constitutiva de nuestra experiencia: así como, habitualmente -aunque no siempre- lo que ocurre se nos presenta como dotado de sentido, también suele presentársenos como dotado de un sentido moral, como más o menos bueno o malo, moralmente apropiado, amoral o inmoral (Balbi, 2017). Si, entonces, el sentido moral es una parte integral del sentido, incluyendo el de aquellos comportamientos que aparecen como 'interesados', y todo ello es producido socialmente, puede concluirse que todo comportamiento es -al menos potencialmente- a la vez 'moral' y 'pragmático'. En este sentido, he sugerido anteriormente (Balbi, 2017) que las formas características en que distintos conjuntos de actores socialmente situados se plantean sus fines y tratan de concretarlos pueden ser entendidas como distintos 'pragmatismos cognitiva y moralmente informados'; esto es, como modalidades socialmente específicas de establecer metas y procurar concretarlas que responden a determinadas orientaciones cognitivas y morales.

La política no constituye una excepción en lo relativo a esto: tanto el entendimiento de los actores respecto del hacer política -cómo perciben y entienden inmediatamente los asuntos que tienen entre manos- como sus conceptualizaciones y reflexiones sobre el particular están informados por axiologías socialmente específicas que deben ser entendidas como un aspecto de la cognición misma (Balbi, 2007, 2014). Así, cualquier corriente política relativamente duradera tiende inevitablemente a desarrollar una forma específica de pragmatismo (o, según el caso, varias) que ha de ser entendido como un aspecto de su manera (o sus maneras) de concebir la actividad política.

A fin de no reificar a estas arrancándolas del flujo histórico, apelo a la noción de 'concepciones nativas de política' (Balbi, 2007, 2014), en la que el vocablo 'nativas' opera como un significante vacío que sirve apenas para recordar que nos encontramos en el plano analítico de las perspectivas nativas, que estamos hablando siempre de las concepciones y formas de actuar de actores concretos, socialmente situados. Las concepciones nativas de política son formas socialmente situadas de entender la política y de hacerla cuyo foco son las maneras en que los actores entienden los qué, para qué, cómo y porqué del hacer política. Se trata de entramados dinámicos de 'modos de conocer' (Harris, 2007) la política; conocimientos al respecto provisoria y temporalmente establecidos, y formas específicas de actuar en política, siendo que sus mutuas relaciones son constitutivas de su producción y reproducción. Por un lado, los conocimientos operan como condiciones de posibilidad de los actos de conocimiento y de las prácticas políticas, los cuales los reproducen y contribuyen en mayor o menor medida a transformarlos; por otro lado, los modos de conocimiento - en el sentido de la "línea continua de su reelaboración por la práctica humana entre uno y otro contexto" (Harris, 2007, p. 6, mi traducción) - dan un sustento imprescindible a las prácticas políticas al tiempo que son reproducidos y/o transformados por ellas. Finalmente, las prácticas políticas son, en sí mismas, tanto puestas en práctica de los conocimientos disponibles como 
prácticas de conocimiento. Los tres elementos -que solo cabe distinguir plenamente a fines analíticos- forman, entonces, un entramado que siempre es más o menos dinámico, donde las prácticas se fundan en conocimientos a los que pueden reconfirmar, complejizar, matizar o poner en tela de juicio.

Por otra parte, las concepciones nativas de política no tienen un carácter sistemático ni están dotadas de una coherencia lógica porque son entramados dinámicos de prácticas y conocimientos (y no, precisamente, conocimientos dados, aislados de la práctica) y porque gran parte de estos tienden a permanecer en un estado implícito, operando de manera prerreflexiva. Así, como he mostrado al analizar el lugar ocupado por las organizaciones partidarias en las prácticas políticas de los peronistas (Balbi, 2014, p. 35), las concepciones de política de cualquier sector político habilitan una multiplicidad de prácticas heterogéneas que, aunque a los ojos de un observador aparezcan como mutuamente contradictorias, deben ser entendidas como resultados de la aplicación de los mismos principios de producción en distintos contextos de acción.

Por último, cuando hablo de las concepciones radicales de política me estoy refiriendo a una 'familia' de formas históricamente interrelacionadas de entender y de desarrollar la actividad política que son específicamente 'radicales' tan solo, en tanto y en cuanto se trata de productos históricos del accionar de los hombres y mujeres que han participado y/o participan de la vida política del radicalismo. De allí el uso del plural: las formas de entender la política y de desarrollarla asociadas a cualquier sector no pueden ser sino un conjunto, siempre fluido y de límites imprecisos y cambiantes, de entrelazamientos de conocimientos y prácticas que derivan unos de los otros, pues se han desarrollado en el curso de procesos sociales interrelacionados. Es en este sentido que apelo a la metáfora de la familia: se trata de concepciones emparentadas históricamente, lo que debe ser considerado a la vez como un dato relevante, informativo y como un problema a investigar (Balbi, 2014). En este caso, veremos que las concepciones radicales de política se emparentan con las de los distintos sectores conservadores de fines del siglo XIX y comienzos del XX.

\section{El republicanismo de los radicales}

Sostengo, entonces, que las formas en que los radicales contemporáneos entienden la política y la hacen, las maneras en que ellos entienden los qué, para qué, cómo y porqué del hacer política - esto es, las concepciones radicales de política- comportan cierto pragmatismo cognitiva y moralmente informado que tiene un carácter socialmente situado y ha sido producido y re-producido a lo largo de la historia del radicalismo y sus derivaciones. Para simplificar un poco relaciones que son complejas, me permitiré sintetizarlo en su forma actual predominante, esbozando cinco rasgos que le son característicos.

Primero, las instituciones republicanas aparecen como el objeto eminente, axiológico, del hacer política y, a la vez, como su conjunto de recursos prácticos clave. Segundo, el propio partido es concebido de manera inseparable como el único orientado realmente a hacer lo necesario por el bien de esas instituciones y como el conjunto de recursos imprescindibles para asumir esa tarea. Tercero, cualquier maniobra política a la que pueda atribuírsele un objetivo institucional y/o que sea desarrollada por el partido o en nombre de éste, está dotada desde el vamos de un principio de legitimación en términos morales independientemente de cuáles sean sus características. Cuarto, puesto que este hacer política se funda en un entendimiento prerreflexivo y que el conocimiento no conforma un sistema coherente, tanto las prácticas que están efectivamente orientadas a preservar y perfeccionar las instituciones como aquellas que atentan contra estas pueden ser concebidas y públicamente expresadas en los mismos términos moralizantes y entrelazarse sin que, por lo general, aparezcan en principio 
como contradictorias a los ojos de los propios actores. ${ }^{4} \mathrm{Y}$ quinto, como contracara de la relación privilegiada que se supone existente entre el partido y las instituciones de la República, la descalificación de los adversarios políticos -sean de otros sectores políticos o del propio- en términos moralizantes se torna, a la vez e inextricablemente, en una tendencia totalmente naturalizada y en un recurso político privilegiado. Todos estos rasgos se implican mutuamente, ${ }^{5}$ y moldean una forma característica de desarrollar las prácticas políticas que supone su orientación sistemática hacia objetivos institucionales y una igualmente sistemática tendencia a apropiarse de las instituciones, haciendo de ellas un recurso para su despliegue.

\section{La UCR y la defensa de las instituciones republicanas en el origen de las concepciones radicales de política}

El origen tanto del énfasis radical en la necesidad de una depuración y defensa de las instituciones republicanas como de la centralidad atribuida a la propia UCR de cara a esa empresa se encuentra en su nacimiento como un partido del orden conservador que carecía de diferencias sociológicas e ideológicas sustanciales con el Partido Autonomista Nacional (PAN) de Julio A. Roca, Carlos Pellegrini y Miguel Juárez Celman, la Unión Cívica de Bartolomé Mitre y otros partidos conservadores (Hora, 2001; Míguez, 2012; Reyes, 2015). Puesto que, en su mayoría, los dirigentes radicales eran hombres asociados a sectores de la oligarquía terrateniente y, en rigor, su exclusión de las posiciones políticas a que aspiraban era apenas el producto de acuerdos entre dirigentes que se traducían en el efectivo reparto de los cargos conseguidos en elecciones fraudulentas, la representación de su propia actividad política como una empresa moral era claramente funcional a sus objetivos y se aparecía naturalmente a sus propios ojos como la razón de ser de su oposición a los otros partidos. De hecho, las disputas entre los partidos del orden conservador tendían, hacia fines del siglo XIX, a desarrollarse en esos términos (Alonso, 2000; Hirsch, 2012; Míguez, 2012; Reyes, 2015), habida cuenta de sus semejanzas ideológicas y su escasa consolidación institucional. Al referirse a la situación en la política bonaerense de la década de 1890, Roy Hora (2001) observa que lo "que se criticaba era, principalmente, un estilo de acción política orientado a la exclusión de la oposición" (p. 26).

Esta concepción moralizante fue la base de la estrategia revolucionaria seguida inicialmente por la UCR, que implicaba la aceptación del procedimiento consistente en hacer uso de la fuerza para romper con la institucionalidad vigente. En efecto, el recurso a las armas era entendido como orientado a defender a las instituciones pues se asumía que estas eran sistemáticamente amenazadas por las prácticas políticas del partido de gobierno. La historiografía reciente muestra que este modo de intervención política hunde sus raíces en una larga tradición -denotada por un uso ponderativo del vocablo 'revolución' - en la que el uso de la fuerza era considerado como un deber cívico frente al despotismo (Sabato, 2003; Hirsch, 2012; Reyes, 2015), y que se inserta en el contexto de un escenario político caracterizado por el hecho de que la oposición al gobierno del PAN se asentaba sobre el diagnóstico de que tanto este como la sociedad se encontraban en un estado de 'degeneración' o 'corrupción' y de que era necesario proceder a su 'regeneración' (Hirsch, 2012; Reyes, 2015).

Esta disposición moralizante, que asociaba el accionar y aún la existencia misma de la UCR a un deber cívico, comenzó a tomar una forma distintiva bajo el liderazgo de Leandro N. Alem, cuyo pensamiento fue influenciado por la filosofía de Immanuel Kant (Passalacqua, 1984) y se profundizó de la mano de Hipólito Yrigoyen, cuyas ideas políticas exhiben una fuerte influencia del krausismo español ${ }^{6}$ (Passalacqua, 1984), siendo estas fuentes filosóficas las que aportaron sus rudimentos conceptuales y retóricos. También puede decirse que esa disposición se alimentó del estilo del liderazgo
4. Cuando surge ese tipo de contradicciones, la misma inconsistencia lógica de estas concepciones de política habilita su resolución mediante el recurso a 'elaboraciones secundarias' (Evans-Pritchard, 1976).

5. Todo esto tiene como correlato el desarrollo de un panorama similar en cuanto a las formas en que los radicales se vinculan con todos los ámbitos institucionales que son objeto de su actuación, de modo que su 'republicanismo' se entiende mejor como el elemento central de una orientación cognitiva y moral más amplia que podríamos caracterizar como 'institucionalista'. Pero este es un tema que no puedo desarrollar aquí.
6. Escuela de pensamiento basada en los escritos del filósofo alemán Karl Christian Friedrich Krause (1781-1832). 
emergente de Yrigoyen que, como ha observado Tulio Halperín Donghi (2004), hubo de asentarse sobre un férreo control del partido debido a que él no disponía de otros recursos para acumular poder, a diferencia de Roca o Mitre, que conservaban cierto margen de independencia respecto de los movimientos políticos de los que se servían porque sus posiciones también tenían raíces en su condición de altos jefes militares.

Pero, en una aparente paradoja, esas ideas y la estrategia revolucionaria que se basaba en ellas estuvieron desde un comienzo en tensión con la aspiración de los dirigentes radicales a llegar a posiciones de gobierno (Alonso, 2014). Diversos sectores radicales no las aceptaban plenamente y se inclinaban a promover la incorporación del partido al juego electoral, tendencia que parece haberse acentuado en la medida en que paulatinamente la UCR fue concitando el apoyo de sectores de la población urbana. El relativo fracaso de todas las intentonas armadas tendió a fortalecer esta tendencia a la transformación de la UCR en un partido como cualquier otro, orientado a promover el acceso de sus dirigentes al Estado por la vía electoral, terreno donde Yrigoyen y sus correligionarios no dudaron en emplear los mismos métodos que criticaban a sus adversarios (Hora, 2001). Así, contra lo que registra habitualmente la memoria histórica de los radicales contemporáneos, la UCR comenzó a participar en elecciones en 1892 y lo hizo regularmente en la Capital Federal y en la provincia de Buenos Aires hasta 1898 (Hora, 2001; Alonso, 2014). De hecho, sus buenas performances -superó el 50\% de los votos en la ciudad en 1894 y llegó a ser el partido más votado en la provincia en 1895- dieron lugar a una marcada moderación de sus críticas a los gobiernos conservadores y a un completo abandono de las referencias a la revolución (Hora, 2001; Alonso, 2014). Sin embargo, el desempeño electoral del radicalismo porteño se desplomó a partir de 1895 (Alonso, 2014) y una serie de disputas internas entre Hipólito Yrigoyen y Bernardo de Irigoyen supuso la desarticulación del yrigoyenismo en la provincia de Buenos Aires porque su líder ya no fue capaz de garantizar el acceso de sus hombres a cargos públicos, lo que acabó con el breve esplendor electoral del radicalismo bonaerense (Hora, 2001).

Curiosamente, este retroceso fue capitalizado por la UCR en la segunda mitad de la década de 1910, cuando más de diez años de ausencia de los procesos electorales le permitieron tender un manto de silencio sobre su historia de acuerdos con autonomistas y mitristas, y se presentó entonces como "el único impugnador moral del régimen, y como una fuerza política sin más vínculos con el pasado político de la Argentina que su voluntad de abolirlo" (Hora, 2001, p. 28). Este resurgimiento se dio de la mano de una profunda identificación del radicalismo con la nación: en efecto, los temas ya establecidos del respeto por la Constitución, la limpieza de los comicios y la naturaleza moral del accionar radical fueron reformulados en términos que revelan la influencia del krausismo, lo que da lugar a la idea de que la UCR no era un partido sino un movimiento que encarnaba la Causa del combate contra el Régimen y se identificaba con la Nación misma, de la cual sería la encarnación (Puiggrós, 1969; Passalacqua, 1984). Así, por ejemplo, Yirigoyen escribe de la UCR que es "la genuina encarnación de las más puras y vigorosas energías de la Patria, que absorbe en su defensa todas las fuerzas morales, intelectuales y reales", y aun que es "la Patria misma" (Primera carta al Doctor Molina, septiembre de 1919; citado en Del Mazo, 1984, p. 75).

7. Esta tendencia a deslegitimar a los adversarios se remonta al origen de la propia UCR, en la década de 1890 . Al respecto, véase Alonso (2000).
La contracara de esta representación de la UCR era la descalificación de los restantes partidos en tanto representantes de intereses sectoriales que se encaramaban en el poder a través de prácticas corruptas. ${ }^{7}$ Olvidando selectivamente el origen de sus fundadores y principales líderes, el Manifiesto Revolucionario del 4 de febrero de 1905 reza:

Los partidos políticos son meras agrupaciones transitorias, sin consistencia en la opinión, sin principios ni propósitos de gobierno. Desprendidos los unos del régimen que domina al país, procedentes los otros de defecciones a la causa de su reparación, el anhelo común es la posesión de los puestos públicos. [...] La oposición 
pierde así sus condiciones esenciales para el bien público, se convierte en escuela perniciosa y perturbadora y en un exponente de la depresión general. (citado en Bortnik, 1989, p. 76)

La descalificación general de los restantes partidos y del juego electoral sería la base de la estrategia de la abstención revolucionaria con que el radicalismo yrigoyenista transitaría la primera década del siglo pasado, ${ }^{8}$ y produjo

un socavamiento sistemático de las autoridades nacionales [...] mostrando al régimen como una mera excrecencia irrepresentativa, al tiempo que el peso efectivo de un radicalismo que eludía el camino del comicio, denunciado como fraudulento, era imposible de mensurar. (Aboy Carlés, 2013, p. 40)

Este camino llevaría a Yrigoyen a la presidencia de la República, Ley Sáenz Peña mediante. Significativamente, dicha ley

vino a consagrar una visión totalizadora de la sociedad en clave espiritual: la representación política estaba llamada a expresar el alma de la nación, cuyo contenido concreto Sáenz Peña no dudaba en reconocer primero en su propia voz y, más ampliamente, en la del grupo pensante del cual era miembro. (Privitellio, 2004, p. 4; las itálicas son del original)

El movimientismo yrigoyenista no representaba sino una variante de esa manera de entender a la nación (Halperín Donghi, 2004; Privitellio, 2004). Se observa, entonces, un entrelazamiento de las concepciones de política de los sectores reformistas del conservadorismo y de los líderes radicales que atestigua las ya mencionadas semejanzas existentes entre sus orígenes, condiciones sociales y programas.

El proceso que llevó a Yrigoyen a la presidencia exhibió nuevamente la tensión entre la concepción yrigoyenista de política y las presiones emergentes de las posibilidades ciertas de llegar al poder por la vía electoral. Entrada la segunda década del siglo, el líder radical aún aspiraba a la toma del poder por la vía de las armas, y se oponía a las exigencias de diversos sectores partidarios en cuanto a deponer la abstención y participar de diversas elecciones provinciales. Sin embargo, no pudo evitar que la UCR santafesina se presentara en las elecciones provinciales de 1912 -las primeras a realizarse tras la reforma electoral-, donde obtuvo un claro triunfo que, sumado a la actitud aperturista del sector reformador del conservadorismo, dejó en claro que la vía electoral estaba abierta para que el radicalismo llegara a ocupar posiciones de relevancia a nivel nacional. Esto condujo, en fin, a la candidatura y el triunfo de Yrigoyen en las elecciones de 1916.

Yrigoyen, sin embargo, trató de gobernar en función de la concepción de la UCR como encarnación de la nación misma -bajo su propio liderazgo, claro está-. Ello se reflejó en "la más agresiva política de intervenciones federales hasta entonces desarrollada" (Aboy Carlés, 2013, p. 41), que alcanzó a la concreción de 19 entre 1916 y 1922 . El gobierno desarrolló una doctrina según la cual el Poder Ejecutivo, encarnado por Yrigoyen, corporizaba a la soberanía entendida como ejercida de manera indivisible dentro de la unidad nacional -y no como fragmentada en un cierto número de soberanías provinciales-, de modo que cualquier revés electoral daba lugar a acusaciones de corrupción en los comicios y a la subsecuente intervención federal (Aboy Carlés, 2013). En esta dinámica encuentra un nuevo desarrollo la predisposición de los radicales a interrumpir el orden institucional en defensa de las propias instituciones: bajo esta lógica, incluso los gobiernos radicales que no respondían al liderazgo del presidente eran sospechosos de ilegitimidad y tendían a ser intervenidos (Aboy Carlés, 2013).
8. Es interesante observar que, durante ese período, la UCR era la única agrupación política que presentaba las características de un partido político en el sentido moderno de la expresión. 
Sin embargo, con el acceso de Yrigoyen a la presidencia, la concepción de la UCR como un movimiento entra en una lenta decadencia y se consolida paulatinamente su representación como un partido político, ya no en un sentido peyorativo, sino en el de un actor legítimo entre otros en el marco del orden institucional. Empero, como veremos, persistiría una suerte de sello moral que, a los ojos de sus integrantes, distingue a la UCR de los restantes partidos.

Yrigoyen desarrolló una estrategia de ampliación de su base política a partir de la extensión de la organización en comités, especialmente en Buenos Aires y las principales ciudades. Esta práctica suponía, entre otras cosas, el nombramiento de numerosos empleados públicos que eran afiliados del partido recomendados por los caudillos locales que presidían los comités, fuera mediante la creación de nuevos cargos o el aprovechamiento de vacantes en la estructura existente (Persello, 2000), y la disposición de fondos públicos para satisfacer cuestiones locales por medio de esos mismos dirigentes. Todo ello vino a consolidar la importancia que la estructura partidaria tenía para los radicales, tal como se refleja en el desarrollo de "conflictos y tensiones en el interior del partido gobernante" en relación con el tema de los nombramientos en el Estado que dieron lugar a "una extrema faccionalización" (Persello, 2000, p. 151): el naciente único partido moderno del país se convertía crecientemente en un espacio de poder significativo, lo que agregaba un enorme valor práctico al valor moral de que ya estaba dotado en tanto encarnación de la Nación misma o-como empezaba a parecer crecientemente- de la más pura representación de sus intereses. De esta forma, la valoración axiomática previa de la UCR como movimiento mutaría progresivamente hacia su valoración, igualmente axiomática, en tanto el único partido que realmente estaría comprometido en la defensa de las instituciones de la República.

Este proceso, con sus tensiones y contradicciones, se prolongaría hasta la caída del segundo gobierno de Yrigoyen, en 1930, e incluso entonces seguiría bajo una forma renovada: los sectores antipersonalistas y alvearistas consideraron que el alzamiento golpista había sido necesario para defender a las instituciones que la corrupción, el personalismo, el autoritarismo y la ineficacia del gobierno amenazaban, y asumieron que, en tanto radicales, correspondía que acompañaran el proceso de reconstrucción para garantizar su éxito, con el resultado de que -en un proceso no exento de tensiones y disputas- se tornaron en partidos del régimen (Ciria, 1986, p. 172; Macor, 2001). En la práctica, esos sectores del radicalismo estaban iniciando una tendencia que se repetiría durante todo el siglo pasado a apoyar los golpes de Estado y las democracias restringidas en nombre de la defensa de las instituciones republicanas, al tiempo que reinventaban la ya añeja tradición de aceptación del uso de la fuerza que la UCR abrazara desde su fundación.

Luego, la irrupción de Perón y el desplazamiento de la UCR a la condición de segunda fuerza electoral promoverían nuevas reafirmaciones de la identificación de la UCR con la defensa de las instituciones republicanas que el peronismo supuestamente ponía en peligro, pero ya no su apartamiento del juego electoral, estrategia que hasta la fecha nunca ha sido retomada pues la fuerte consolidación de la concepción del radicalismo como un partido político tendió a excluirla. Así, en 1956 Arturo Frondizi abjuró expresamente de la identificación plena del radicalismo con la nación (Aboy Carlés, 2001), con lo que la concepción movimientista de la UCR perdió centralidad incluso entre los sectores radicales que se consideraban como herederos directos del yrigoyenismo.

Como cabría esperar, la reformulación del valor axiomático atribuido a la UCR en el sentido de su representación como un partido político insoslayablemente orientado hacia la defensa de las instituciones de la República, condujo a que en las concepciones radicales de política se valoraran per se también a los partidos en abstracto y al sistema de partidos en general. Pero sería engañoso abordar esta cuestión como si se tratara 
apenas de un asunto de principios - pues es mucho más que eso-. Indicios del punto hasta el cual las valoraciones morales y prácticas no pueden ser entendidas separadamente son los hechos -solo aparentemente paradójicos- de que los radicales también hayan conservado una marcada predisposición a deslegitimar a sus adversarios políticos que se hace presente toda vez que estos se muestran reiteradamente más exitosos que ellos en la arena electoral, y de su recurrente participación en rupturas del orden institucional y regímenes políticos irregulares.

\section{El republicanismo de los radicales como un pragmatismo cognitiva y moralmente informado}

Parece posible afirmar, entonces, que para 1930 ya se habían establecido los lineamientos generales del pragmatismo cognitiva y moralmente informado que, con variaciones, caracteriza al radicalismo hasta el día de hoy. La concepción del propio hacer político y su partido como inexorablemente orientados hacia el objetivo axiológico de la defensa de las instituciones republicanas constituye una forma distintiva de entender el porqué, el para qué y el cómo de la política siempre y cuando sean los mismos radicales quienes la practican; a la vez, el partido y las propias instituciones de la República se les aparecen como los recursos fundamentales a controlar y desplegar en ese hacer política, tanto porque el objetivo netamente institucional de este les confiere una clara relevancia práctica, como porque uno y otras revisten para ellos un valor axiomático, sin que ambas fuentes de su interés sean diferentes para ellos. Así es que prácticas que a ojos de terceros contradicen claramente sus preocupaciones republicanas -como la vulneración de procedimientos institucionales, la suspensión de las operaciones de las instituciones y la negación de la legitimidad de los adversarios políticos- aparecen desde el punto de vista de los radicales como, cuanto menos, potencialmente legítimas, pues se asume que sus objetivos últimos son virtuosos y que quienes las desarrollan - por el hecho de actuar en nombre del partido o, simplemente, porque son radicaleshabrán de apegarse estrictamente a aquellos. De esta suerte, la preocupación moralizante de los radicales por las instituciones republicanas y sus prácticas institucionalmente dudosas o sencillamente dañinas no solo son perfectamente compatibles sino que se implican mutuamente. ${ }^{9}$

Esto significa que no podemos conformarnos con denunciar la supuesta forma en que los radicales 'traicionarían' sus 'convicciones' ni con dar por explicado su proceder como manifestación de una cierta 'ideología' falsamente republicana que sería, en realidad, liberal. La situación es mucho más compleja y nuestro aporte específico como antropólogos sociales debe ser el de contribuir a explicarla en toda esa complejidad. El punto clave es que, en la medida en que sus concepciones de política tienen por elemento central a una cierta axiología que pone a las instituciones republicanas en el foco de su hacer política, los radicales y exradicales están particularmente predispuestos a desplegar un lenguaje 'republicano' en función de objetivos políticos cambiantes y, por supuesto, a decir en ese lenguaje lo que las circunstancias políticas hagan conveniente: lejos de tratarse de una contradicción -hablando en términos objetivadores- entre sus orientaciones valorativas y la orientación pragmática de sus actos, no hay en esto más que una mutua implicación y conformación de ambas.

“'La República', artículo retórico, conspira hoy contra la República entendida como valor substantivo”, decía - no sin razón-Adamovsky (2017, p. 63). Podemos ahora ver que, en lo que respecta a los radicales, el 'artículo retórico' y el 'valor substantivo' no son sino dos caras de una misma moneda forjada a lo largo de la ya más que centenaria historia de su partido. No debería extrañarnos, pues, que durante la década kirchnerista, al cabo de más de veinte años de democracia, numerosos políticos radicales se mostraran dispuestos a anunciar la inminencia - y hasta a postular la necesidad- de
9. Esta mirada suscita inevitablemente la pregunta sobre si los radicales creen realmente en estas ideas respecto de su propio hacer política. Empero, como he mostrado anteriormente (Balbi, 2007), aunque no es posible determinar si uno u otro dirigente o militante está más o menos imbuido de la axiología republicanista, de manera que no podemos saber si actúa con mayor o menor 'convicción', ello no comporta un problema analítico porque todas las prácticas políticas de los radicales - desde las que pueden parecernos meramente pragmáticas hasta las que aparentan fundarse exclusivamente en los valores republicanos- son el producto del despliegue, en distintos contextos de acción, de una serie de variaciones sobre un mismo conjunto de orientaciones cognitivas y morales. En este sentido, la forma en que cada radical se relaciona íntimamente con esas orientaciones resulta indiferente a los fines del análisis. 
10. La lista es casi inagotable: el intento de nombrar jueces para la Corte Suprema en comisión apelando a un decreto; la maniobra por la cual Cambiemos se apoderó de un asiento en el Consejo de la Magistratura mediante la formación de un fugaz interbloque al solo efecto de desplazar al Frente para la Victoria de su condición de primera minoría parlamentaria; el nombramiento de funcionarios cuyos conflictos de intereses los descalifican para los cargos que ocupan; la licuación de la deuda del grupo empresario de los Macri por la oscura quiebra del Correo Argentino; la escalada represiva contra las protestas sociales; la violación en ese marco de derechos humanos que -cabe recordarlo- constituyen en nuestro país instituciones de la República en la medida en que revisten el rango constitucional; el incumplimiento de resoluciones de la Corte Interamericana de Derechos Humanos por parte de la justicia de la provincia de Jujuy, bajo control político del gobernador radical Gerardo Morales; la persecución por vía judicial a políticos opositores y dirigentes sociales; etcétera.

11. Lo mismo puede decirse, en términos generales, respecto de los diversos sectores desprendidos del radicalismo desde la debacle de la Alianza en 2001. la caída de un gobierno elegido por el voto popular, cosa que en la práctica suponía promoverla activamente. Tampoco sorprende que en el contexto actual, en el que la UCR integra como socio muy minoritario la coalición que sostiene al gobierno de la nación, sus más altos dirigentes y funcionarios de varios niveles avalen públicamente, participen de y hasta emprendan personalmente cursos de acción que claramente son violatorios de formalidades institucionales del orden republicano de no poca importancia. ${ }^{10} \mathrm{Y}$ hasta resulta esperable que no pocos de esos mismos políticos y funcionarios manifiesten entre bambalinas su preocupación e incluso su rechazo respecto de una u otra de esas maniobras y medidas, ocupándose cuidadosamente de dejar que esto trascienda por medio de declaraciones hechas a medios de prensa off the record que les permiten posicionarse en la interna radical en términos moralizantes. En efecto, las 'dobles varas' esgrimidas para evaluar las actitudes para con la república a que también se refería Adamovsky no son tales si se las mira desde el punto de vista de los radicales, para quienes los únicos intérpretes realmente autorizados del bienestar de aquella son ellos mismos y sus órganos partidarios. ${ }^{11}$

Todo indica que estamos ante un tipo de pragmatismo cognitiva y moralmente informado que, a pesar de sus semejanzas en cuanto a la apelación a un lenguaje moralizante centrado en la cuestión republicana y al profuso despliegue de dobles varas para establecer diferenciaciones políticas, difiere en sus fundamentos del que cabe atribuir al PRO, cuyo propio republicanismo parece remitir centralmente al paso de muchos de sus dirigentes y cuadros por fundaciones, think tanks y ONG (Vommaro y Morresi, 2015). Un análisis completo del panorama actual de las orientaciones políticas de los radicales exigiría, además de las tareas mencionadas páginas atrás, examinar las formas en que, desde hace algunos años, las apelaciones pragmáticas a argumentos republicanistas desarrolladas por ellos, los exradicales, los macristas y ciertos políticos peronistas se constituyen mutuamente en un escenario marcado tanto por el predominio de orientaciones neoliberales en todos esos sectores como por su común enfrentamiento con el kirchnerismo.

\section{A modo de conclusión}

El del radicalismo no es sino un caso entre tantos otros de la forma inextricable en que, en la política, se interrelacionan las orientaciones cognitivas y morales. Una axiología es siempre una parte integral de una pragmática específica y es, a la vez, el producto de su despliegue. A este respecto, la política no se diferencia cualitativamente de cualquier otra actividad social: si acaso hay diferencias, estas son más bien de grado y se relacionan con las fuertes exigencias de adaptación a coyunturas rápidamente cambiantes que supone la política.

Lejos de ser algo extraño, entonces, resulta de todo punto de vista esperable que una orientación axiológica hacia la defensa de las instituciones resulte en prácticas políticas susceptibles de dañarlas, incluso seriamente. En la vida real, la acción moralmente fundada y la orientada a fines no se separan: de hecho, ni siquiera se distinguen claramente una de la otra a los ojos de sus protagonistas (Balbi, 2017). Al contrario, la moral es constitutiva de los intereses de los actores; las preferencias morales entran como elementos constitutivos de la acción -que, a fin de cuentas, es teleológica por naturaleza-. Así es, en suma, que los radicales y exradicales pueden llegar a ser una amenaza para las instituciones de nuestra república $-y$, lamentablemente, suelen serlo-, no porque no sean republicanos sino precisamente porque, a su manera, lo son. 


\section{Financiamiento:}

"Este documento es resultado del financiamiento otorgado por el Estado Nacional, por lo tanto queda sujeto al cumplimiento de la Ley № 26.899”. La investigación que sirvió de base al texto ha sido parcialmente financiada por la Universidad de Buenos Aires en el marco de la Programación UBACyT 2014-2017. Cód.: 20020130100330BA. Argentina. Título del proyecto: "Análisis etnográfico y comparativo de la producción social de distintos niveles de organización político-administrativa (II): relaciones sociales y escala en los procesos políticos."

\section{Agradecimientos:}

Versiones previas de este análisis fueron presentadas en agosto de 2016 en el Ciclo “Perspectivas en Antropología y Etnografía” (Programa de Postgrado en Antropología Social - Universidad Nacional de Misiones), con comentarios a cargo de Laura Ebenau, y en noviembre de 2017 en el Encuentro “Antropología Política y Estado” (Universidad Nacional de Río Negro - Sede Andina), donde tuve la oportunidad de dialogar al respecto con Eva Muzzopappa, Ricardo Abduca, Ana Ramos, Mercedes Barros, Celeste Ratto, Constanza Casalderrey, María Emilia Sabatella y Emmanuel Vargas. Agradezco sus valiosos aportes, algunos de los cuales no se reflejan en este texto pero alimentan la continuidad de mi trabajo. 


\section{Q Referencias bibliográficas}

" Aboy Carlés, G. (2001). Repensando el populismo. En XXIII Congreso Internacional Latin American Studies Association. Washington DC, Estados Unidos, Latin American Studies Association. Recuperado de http://lasa.international.pitt.edu/Lasa2001/AboyCarlesGerardo.pdf

" Aboy Carlés, G. (2013). El radicalismo yrigoyenista y el proceso de nacionalización del espacio político. Una interpretación a través de los usos del concepto de hegemonía. Identidades, 4, 33-47.

"Adamovsky, E. (2017). El cambio y la impostura. La derrota del kirchnerismo, Macri y la ilusión PRO. Buenos Aires: Planeta.

"Alonso, P. (2000). Entre la revolución y las urnas. Los orígenes de la Unión Cívica Radical y la política argentina en los años '9o. Buenos Aires: Sudamericana / Universidad de San Andrés.

» Alonso, P. (2014). La Unión Cívica Radical: fundación, oposición y triunfo (1890-1916). En M. Lobato (Ed.), El progreso, la modernización y sus límites (1880-1916) (pp. 209-259). Buenos Aires: Sudamericana.

" Balbi, F. A. (2007). De leales, desleales y traidores. Valor moral y concepción de política en el peronismo. Buenos Aires: Antropofagia.

" Balbi, F. A. (2012). La integración dinámica de las "perspectivas nativas" en la investigación etnográfica. Intersecciones en Antropología, 13(2), 485-499.

» Balbi, F. A. (2014)....quiero andar con mucha libertad. Consideraciones en torno de los lugares de las organizaciones partidarias y de la conducción en la praxis política de los peronistas. En J. C. Melon y N. Quiroga (Comps.), El peronismo y sus partidos. Tradiciones y prácticas políticas entre 1946 y 1976 (pp. 17-53). Rosario: ProHistoria.

» Balbi, F. A. (2016a). A moral como parte integral da produção da vida social. Uma leitura heterodoxa dos escritos de Emile Durkheim. Sociologia \& Antropologia, 6(3), 755-778.

» Balbi, F. A. (2016b). Moral, ética y codificación en la antropología sociocultural argentina. Avá, Revista de Antropología Social, 28, 43-71.

" Balbi, F. A. (2017): Moral e interés. Una perspectiva antropológica. PUBLICAR en Antropología y Ciencias Sociales, año XV, XXIII, 9-30.

»Bloch, M. (2012). Anthropology and the cognitive challenge. Cambridge: Cambridge University Press.

" Bortnik, R. (1989). Yrigoyen y el primer movimiento. Buenos Aires: Centro Editor de América Latina.

"Ciria, A. (1986). Partidos y poder en la Argentina moderna (1930-1946). Buenos Aires: Hyspamérica.

»Del Mazo, G. (Comp.). (1984). Yrigoyen. Su pensamiento escrito. Avellaneda: Pequén.

»Evans-Pritchard, E. E. (1976). Brujería, magia y oráculos entre los Azande. Barcelona: Anagrama.

»Halperín Donghi, T. (2004). El lugar del peronismo en la tradición política argentina. En S. Amaral y M. Ben Plotkin (Comps.), Perón: del exilio al poder (pp. 19-42). Buenos Aires: EDUNTREF. 
" Harris, M. (2007). Introduction. 'Ways of knowing'. En M. Harris (Ed.), Ways of Knowing. New Approaches in the Anthropology of Knowledge and Learning (pp. 1-24). Oxford: Berghahn Books.

» Hirsch, L. (2012). Entre la “revolución” y la “evolución”. Las movilizaciones del Noventa. PolHis, 5(9), 156-170.

» Hora, R. (2001). Autonomistas, radicales y mitristas: el orden oligárquico en la provincia de Buenos Aires (1880-1912). Boletín del Instituto de Historia Argentina y Americana "Dr. Emilio Ravignani", 3(23), 39-78.

» Johnson, M. (1992). The body in the mind. The bodily basis of meaning, imagination and reason. Chicago / London: The University of Chicago Press.

" Macor, D. (2001). Partidos, coaliciones y sistema de poder. En A. Cattaruzza (Ed.), Crisis económica, avance del Estado e incertidumbre política (1930-1943) (pp. 49-96). Buenos Aires: Sudamericana.

》 Míguez, E. (2012). Gestación, auge y crisis del orden político oligárquico en la Argentina. Balance de la historiografía reciente. PolHis, 5(9), 38-68.

»Passalacqua, E. (1984). Noticia preliminar sobre el pensamiento yrigoyenista. En G. Del Mazo (Comp.), Yrigoyen. Su pensamiento escrito (pp. 7-32). Avellaneda: Pequén.

» Persello, A. V. (2000). Administración y política en los gobiernos radicales, 1916-1930. Sociohistórica, 8, 121-152.

»Privitellio, L. de (2004). Partidos políticos. Historiapolitica.com. Recuperado de http:// historiapolitica.com/datos/biblioteca/privitelio.pdf

"Puiggrós, R. (1969). El yrigoyenismo. Buenos Aires: Jorge Álvarez.

"Reyes, F. (2015). La revolución como mito, la regeneración como promesa. Ideas-fuerza en los orígenes de la Unión Cívica Radical. Ariadna histórica. Lenguajes, conceptos, metáforas, 4, 117-146.

"Sabato, H. (2003): El ciudadano en armas: violencia política en Buenos Aires (1852189o). Entrepasados, 23, 149-169.

"Vommaro, G. y Morresi, S. D. (2015). “La Ciudad nos une”. La construcción de PRO en el espacio público argentino. En G. Vommaro y S. D. Morresi (Comps.), "Hagamos equipo". PRO y la construcción de la nueva derecha en Argentina (pp. 29-70). Buenos Aires: Universidad Nacional de General Sarmiento. 
